\title{
Monetary Policy and the Fisher Effect
}

\author{
Paul Söderlind* \\ Department of Economics \\ Stockholm School of Economics
}

March 4, 1999

\begin{abstract}
Historical estimates of the informational content in the yield curve may not be relevant after a change in monetary policy. This study uses a small dynamic rational expectations model with staggered price setting to study how monetary policy affects the relation between nominal interest rates, inflation expectations, and real interest rates. The benchmark parameters, including the Fed's loss function parameters, are estimated by maximum likelihood on quarterly U.S. data. The policy experiments include stronger inflation targeting and more active monetary policy.
\end{abstract}

\section{Introduction}

The most common way of measuring the Fisher effect is by the slope coefficient in an OLS regression of inflation or inflation expectations (the distinction does not matter if expectations are rational) on nominal interest rates, $\pi^{e}=a+b i+\varepsilon_{t}$. A value of $b$ slightly less than unity is a common result on U.S. data. ${ }^{1}$ This equation can also be used

* Stockholm School of Economics and CEPR. Address: Stockholm School of Economics, PO Box 6501, SE-113 83 Stockholm, Sweden.E-mail: Paul.Soderlind@hhs.se. I thank Magnus Jonsson, Andrew Rose, Glenn Rudebusch, Lars E.O. Svensson, and Anders Vredin for comments.

${ }^{1}$ Mishkin (1992) finds that the $b$ coefficient is around 0.7 in regressions of 3-months ex post inflation on nominal interest rates (monthly data 1953-1990). Söderlind (1998) finds similar numbers for one-year inflation based on both ex post data and several surveys of inflation expectations, with an $R^{2}$ around 0.7 (semi-annual data 1953-1995). 
as an (optimal if normally distributed variables) indicator rule for inflation expectations, $\hat{\pi}^{e}=a+b i$. From the Fisher equation, $i=\pi^{e}+r$ where $r$ is the (risk adjusted) real interest rate, it follows that the indicator rule for the real interest rate is $\hat{r}=(1-b) i$ plus a constant. This study investigates how monetary policy affect these indicator rules and their fit. This is done by first estimating a small macromodel of the U.S. economy and then analyzing the effects on the equilibrium time series process of changing the objectives of the policy maker. For sake of brevity, the attention is focused on one-year interest and inflation rates, but similar results hold for longer maturities.

\section{A Model of Monetary Policy}

This is a modified version of the model in Fuhrer and Moore (1995). The main features of the model are: (i) inflation is persistent; (ii) monetary policy can affect output via the real interest rate and then inflation via a forward looking "Phillips effect"; (iii) monetary policy tries to strike a balance between output and inflation stability while avoiding large movements in the nominal interest rates.

The IS curve for detrended log output, $y_{t}$, is

$$
y_{t}=\alpha_{1} y_{t-1}+\alpha_{2} y_{t-2}+\alpha_{r} r_{t-1}+\varepsilon_{y t},
$$

where $\varepsilon_{y t}$ is an output shock. The long ex ante real interest rate, $r_{t}$, obeys an approximate risk neutral arbitrage condition for a ten year real coupon bond

$$
r_{t}=\frac{1}{41} \sum_{s=0}^{\infty}\left(\frac{40}{41}\right)^{s} \mathrm{E}_{t}\left(i_{t+s}-\pi_{t+1+s}\right),
$$

where $i_{t}$ is the annualized one quarter nominal interest rate (the policy instrument), and $\pi_{t}$ the annualized one quarter inflation rate, $\pi_{t}=4\left(p_{t}-p_{t-1}\right)$. Wage contracts negotiated in $t$ specify a flat nominal wage, $w_{t}$, for three quarters (Fuhrer and Moore (1995) use four). A fraction $\theta_{1} / \theta_{0}$ of these contracts "survive" until in $t+1$, and a fraction $\left(1-\theta_{0}-\theta_{1}\right) / \theta_{0}$ until $t+2$. The log price level is the average of the wage contracts still in effect

$$
p_{t}=\theta_{0} w_{t}+\theta_{1} w_{t-1}+\left(1-\theta_{0}-\theta_{1}\right) w_{t-2} .
$$

Nominal wage contracts are set so the current real contract wage equals the average real 
contract price index, $v_{t}$, expected to hold over the contract period, adjusted for demand pressure and wage/inflation shocks, $\varepsilon_{p t}$,

$$
\begin{aligned}
w_{t} & =p_{t}+\theta_{0}\left(v_{t}+\gamma y_{t}\right)+\theta_{1} \mathrm{E}_{t}\left(v_{t+1}+\gamma y_{t+1}\right)+\left(1-\theta_{0}-\theta_{1}\right) \mathrm{E}_{t}\left(v_{t+2}+\gamma y_{t+2}\right)+\varepsilon_{p t}, \\
v_{t} & =\theta_{0}\left(w_{t}-p_{t}\right)+\theta_{1}\left(w_{t-1}-p_{t-1}\right)+\left(1-\theta_{0}-\theta_{1}\right)\left(w_{t-2}-p_{t-2}\right) .
\end{aligned}
$$

Fuhrer and Moore (1995) close the model by specifying the Fed's reaction function. To discuss monetary policy in terms of policy objectives, I instead let the Fed commit to a policy rule which minimizes the loss function

$$
L_{t}=\mathrm{E}_{t} \sum_{t=0}^{\infty} \beta^{t}\left[q_{y} y_{t}^{2}+\left(1-q_{y}\right) \pi_{t}^{2}+q_{i} i_{t}^{2}\right] .
$$

The model is estimated with maximum likelihood by combining a solution algorithm for linear rational expectations models with a Kalman filter. ${ }^{2}$ The sample is quarterly US data for 1966:II to 1995:IV where $y_{t}$ is taken to be log real GNP per capita detrended with a linear trend, $\pi_{t}$ the quarterly changes in the consumer price index for urban workers, and $i_{t}$ is assumed to differ from the three month T-bill rate by an error term, $\varepsilon_{i t}$. The three shocks are assumed to be iid. normally distributed. ${ }^{3}$

\section{Output versus Inflation Targeting}

Consider putting a larger weight on inflation stability in the Fed's loss function (1) by changing $q_{y}$ from the point estimate of 0.82 to 0.1 . Figures $1 . a-d$ compare the impulse response functions. The important difference is that inflation is now brought under control faster (Figure 1.a) since the Fed reacts stronger to inflation shocks (Figure 1.c). This decreases the standard deviation of inflation by $17 \%$, at the expense of increasing the standard deviations of output by $27 \%$.

With the estimated parameters, the nominal interest rate is a fairly good indicator of inflation expectations, but not of the real interest rate. The indicator rule for one year inflation expectations has a coefficient of 0.8 (on the one year nominal interest rate) and

\footnotetext{
${ }^{2}$ See Söderlind (1999) for a summary of recent advances in solution methods for this class of models.

${ }^{3}$ The estimation results are the following: in the IS curve $\left(\alpha_{1}, \alpha_{2}, \alpha_{r}, \operatorname{Std}\left(\varepsilon_{y t}\right)\right)=$ $(1.39,-0.50,-0.55,0.84)$; in the loss function $\left(q_{y}, q_{i}\right)=(0.82,0.35)$; in the price equations $\left(\theta_{0}, \theta_{1}, \gamma, \operatorname{Std}\left(\varepsilon_{p t}\right)\right)=(0.62,0.29,0.0019,0.19) ;$ and for T-bill $\operatorname{Std}\left(\varepsilon_{i t}\right)=1.41$.
} 
a. Inflation shock $\rightarrow$ inflation

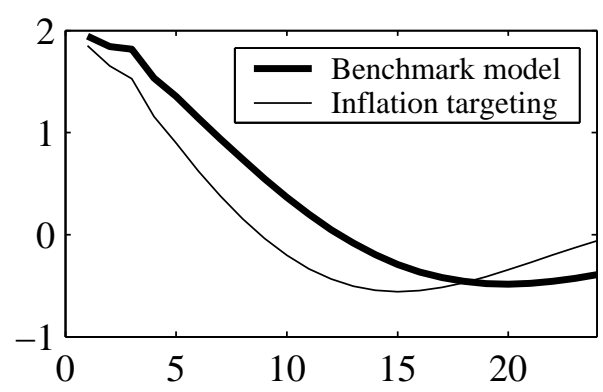

c. Inflation shock $\rightarrow$ interest rate

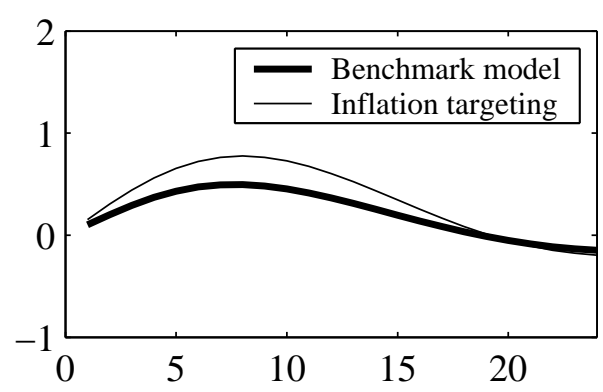

b. Output shock $\rightarrow$ inflation

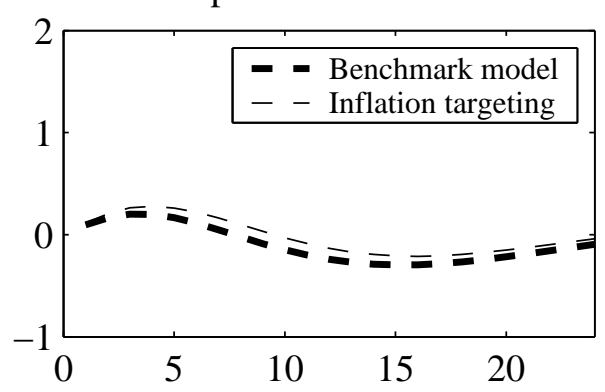

d. Output shock $\rightarrow$ interest rate

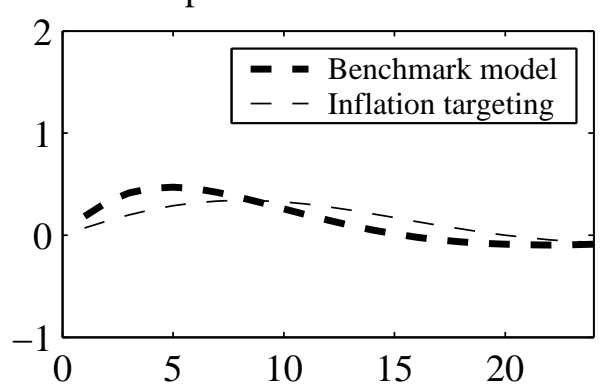

Figure 1: Impulse response functions with estimated parameters and stronger inflation targeting

an $R^{2}$ of $20 \%$. The indicator rule for the real interest rate has a coefficient of 0.2 and an $R^{2}$ very close to zero.

This changes completely with stronger inflation targeting: the nominal interest rate is then uninformative about inflation expectations $\left(b=R^{2}=0\right)$, but a good indicator of the real interest rate $\left(1-b=1\right.$ and $\left.R^{2}=0.5\right)$.

The intuition for this results is that, with the estimated parameters, the main task of the Fed is to stabilize output by cushioning output shocks (inflation shocks are relatively unimportant in this case since they have only small effects on output). This is can be done by changing the nominal interest rate to make the real interest rate offset the output shocks.

With stronger inflation targeting, the Fed instead tries to make the real interest rate move output in order to stabilize inflation. This brings down the volatility of inflation, but increases the volatility of the real interest rate since it takes large movements in output 
to control inflation (the Phillips effect is weak). More of the movements in the nominal interest rate will therefore reflect movements in the real interest rate. ${ }^{4}$ This intuition carries over to inflation expectations and interest rates for longer maturities, because of the strong dynamics (autocorrelation) in the model.

\section{A More Active Monetary Policy}

The central bank cares not only about output and inflation stability but also about interest rate stability, which puts a break on monetary policy. We now consider a more active monetary policy by changing $q_{i}$ in the Fed's loss function (1) from the point estimate of 0.35 to 0.1 . The more active monetary policy means that the Fed raises the short nominal interest rate more after a shock. The main effect is to bring inflation under control faster.

This shift in monetary policy decreases the Fisher effect, $b$ decreases slightly (from 0.8 to 0.57 ). More interestingly, it also increases the information content in the nominal interest rate about both inflation expectations and real interest rates $\left(R^{2}\right.$ increases from 0.2 to 0.35 for inflation expectations and $R^{2}$ from 0 to 0.24 for the real interest rate).

We get some intuition for this result by considering the case where the policy maker is very cautious. In this case. the policy maker raises the nominal interest by fairly little in response to an inflation shock, so the real interest rate will decrease almost as much as inflation expectation increase. This makes inflation expectations and real interest rates strongly negatively correlated, at least if inflation shocks dominate output shocks.

Suppose we forget about this particular model for a while, and that all we know is that inflation expectations and real interest rates strongly negatively correlated and that they are about equally volatile. How should we then interpret an $0.3 \%$ increase in the nominal interest rate? The answer is that we do not know. It could be that inflation expectations increased with $1 \%$ and real interest rate decreased with $0.7 \%$. Equally likely, it could be just the opposite. The nominal interest rate is almost a useless indicator in this case (the $R^{2}$ is very low for both inflation expectations and real interest rates).

Making monetary policy more active takes us out of this situation, since it makes inflation expectations and real interest rates more independent of each other. ${ }^{5}$

\footnotetext{
${ }^{4}$ Let $\sigma=\operatorname{Std}\left(r_{t}\right) / \operatorname{Std}\left(\pi_{t+1}^{e}\right)$ and $\rho=\operatorname{Corr}\left(\pi_{t+1}^{e}, r_{t}\right)$. It can then be shown that $b=(1+\rho \sigma) /\left(1+\sigma^{2}+\right.$ $2 \rho \sigma), R^{2}$ for the $\pi_{t+1}^{e}$ rule is $b(1+\rho \sigma)$, and $R^{2}$ for the $r_{t}$ rule is $(1-b)(1+\rho / \sigma)$. In this case, $\rho$ is almost unchanged at -0.8 , but $\sigma$ increases.

${ }^{5}$ More formally, this policy shift leaves $\sigma$ in footnote 4 almost unchanged at around 0.9 , but increases $\rho$
} 


\section{References}

Fuhrer, Jeffrey C., and George Moore, 1995, Monetary policy trade-offs and the correlation between nominal interest rates and real output, American Economic Review 85, 219-239.

Mishkin, F.S., 1992, Is the Fisher effect for real?, Journal of Monetary Economics 30, 195-215.

Söderlind, Paul, 1998, Nominal interest rates as indicators of inflation expectations, Scandinavian Journal of Economics 100, 457-472.

—, 1999 , Solution and estimation of RE macromodels with optimal policy, European Economic Review 43, 813-823.

from -0.8 to -0.4 . 